\title{
EVIDÊNCIA SOROLÓGICA DA OCORRÊNCIA DE CISTICERCOSE SUÍNA EM CRIAÇÕES NÃO TECNIFICADAS NA REGIÃO DO MUNICÍPIO DE JABOTICABAL, ESTADO DE SÃO PAULO, BRASIL
}

\author{
SEROLOGICAL EVIDENCE OF SWINE CYSTICERCOSIS IN NON-TECHNIFIED \\ REARING FARMS IN JABOTICABAL REGION, STATE OF SÃO PAULO, BRAZIL
}

\author{
H. M. S. ALMEIDA ${ }^{1 *}$, G. A. M. ROSSI ${ }^{1}$, R. P. M. GUIMARÃES-PEIXOTO ${ }^{2}$, E. C. ACEVEDO- \\ NIETO $^{2}$, A. M. C. VIDAL ${ }^{3}$, L. A. MATHIAS ${ }^{1}$, P. S. A. PINTO ${ }^{2}$, L. G. OLIVEIRA ${ }^{1}$
}

\begin{abstract}
RESUMO
O presente trabalho objetivou avaliar a ocorrência de anticorpos contra Taenia solium em suínos criados em propriedades não tecnificadas na Região do Município de Jaboticabal, Estado de São Paulo, Brasil. Para isso, foram coletadas 352 amostras de sangue de animais entre três meses e dois anos de idade em 56 propriedades localizadas nos Municípios de Borborema (2), Guariba (1), Guatapará (2), Ibitinga (1), Itápolis (3), Jaboticabal (18), Monte Alto (4), Motuca (11), Pradópolis (4), Taiaçu (5), Taíuva (1) e Taquaritinga (4). Para diagnóstico dos animais infectados, foi utilizado o teste de ELISA indireto como triagem (sensibilidade $=100 \%$ e especificidade $=98 \%)$ e o Western Blot como confirmatório (sensibilidade $=79,6 \%$ e especificidade $=98,5 \%$ ). A prevalência e o intervalo de confiança a $95 \%$ foram determinados baseados nos resultados obtidos. A prevalência nos animais infectados foi de $6,82 \%$ (I. C. $95 \% 4,18$ - 9,45) e em $28,87 \%$ (I. C. $95 \% 16,74-40,40$ ) das propriedades. Esses elevados valores estão provavelmente relacionados com o baixo nível de adoção de práticas profiláticas durante a criação dos animais. Isso permite a exposiçãoaos fatores de risco encontrados na literatura para a ocorrência da doença, os quais puderam ser observados durante a realização do estudo, como a criação em sistemas free-range, a ausência de sanitários, o fornecimento de água e alimentos possivelmente contaminados e o abate de animais sem inspeção sanitária. Através dessa evidência sorológica da ocorrência de cisticercose em suínos, alertam-se as autoridades sanitárias locais para a promoção de medidas de saúde pública a fim de controlar a ocorrência de $T$. solium, por meio da vacinação dos animais, promoção de educação sanitária em relação ao consumo de carnes não inspecionadas ou indevidamente preparadas, o tratamento em massa de humanos infectados, melhorias em relação ao saneamento básico e não permissão do consumo de águas e alimentos contaminados pelos animais.
\end{abstract}

PALAVRAS-CHAVE: EPIDEMIOLOGIA. SAÚDE PÚBLICA.TAENIA SOLIUM. ZOONOSES

ÁREA TEMÁTICA: Zoonoses

${ }^{1}$ UNESP - Univ. Estadual Paulista, Faculdade de Ciências Agrárias e Veterinárias (FCAV), Departamento de Medicina Veterinária Preventiva e Reprodução Animal, Via de acesso Paulo Castellane, s/n, CEP 14884-900 Jaboticabal, São Paulo, Brasil. *henri_almeida2003@yahoo.com.br

${ }^{2}$ UFV - Universidade Federal de Viçosa, Departamento de Veterinária, Avenida Peter Henry Rolfs, S/N, CEP 36570-900, Viçosa, Minas Gerais, Brasil.

${ }^{3}$ Universidade de São Paulo, Faculdade de Zootecnia e Engenharia de Alimentos (FZEA), Departamento de Medicina Veterinária, Avenida Duque de Caxias Norte 225, CEP 13635-900 Pirassununga, São Paulo, Brasil 